\title{
DETECÇÃO DE BACTERIOCINAS PRODUZIDAS POR Lactobacillus plantarum BN EM MELAÇO DE CANA-DE-AÇÚCAR SOB FERMENTAÇÃO SUBMERSA
}

\author{
JACIARA ZARPELLON MAZO * \\ ERNANI S. SANT'ANNA ** \\ BERNADETTE D.G.M. FRANCO*** \\ ANNA C. S. PORTO * \\ ÂNGELA M. FIORENTINI *
}

\begin{abstract}
Verificou-se a presença de bacteriocinas produzidas por Lactobacillus plantarum BN (microrganismo teste) em caldo com $3 \%$ de melaço de cana-de-açúcar, centrifugado e enriquecido com extrato de leveduras, acetato de sódio e citrato de amônia. Os testes foram realizados em fermentador com volume de trabalho de 3,0 L, sob agitação contínua a $100 \mathrm{rpm}$, temperatura de $30 \pm 0,1^{\circ} \mathrm{C}$, aeração de $0,7 \mathrm{vvm}$, tempo de fermentação de 24 horas e inóculo aproximado de $6,0 \log _{10} \mathrm{UFC} / \mathrm{mL}$, com tomada de amostras em intervalos de 2 horas. O maior número médio de células viáveis foi de 10 $\log _{10}$ ciclos logarítmicos, nos intervalos de 12 a 18 horas de fermentação. $\mathrm{O}$ pH inicial de 6,49, após 24 horas diminuiu para 5,05. A detecção de bacteriocinas foi realizada no sobrenadante obtido por centrifugação do meio de cultivo, pelo método de difusão em orifícios, usando Lactobacillus sakei ATCC 15521 como microrganismo indicador. Verificouse a presença de bacteriocinas no meio de cultivo a partir de 8 horas de fermentação pela formação de halo inibitório, quando o microrganismo encontrava-se na fase exponencial de crescimento. Comprovou-se a natureza protéica da bacteriocina pelo uso da enzima $\alpha$-quimotripsina. A bacteriocina produzida por $L$. plantarum BN apresentou efeito inibitório sobre Listeria monocytogenes ATCC 19112, mas não sobre Staphylococcus aureus ATCC 15489.
\end{abstract}

PALAVRAS-CHAVE: LACTOBACILLUS PLANTARUM BN; BACTERIOCINAS, MELAÇO DE CANA-DE-AÇÚCAR, FERMENTAÇÃO.

* Professora, Mestre, Departamento de Ciência e Tecnologia de Alimentos, Universidade Federal de Santa Catarina (UFSC), Florianópolis, SC.

** Professor, Doutor, Departamento de Alimentos e Nutrição Experimental, Centro de Ciências Agrárias, UFSC. (e-mail: bfranco@usp.br).

*** Professora, Doutora, Faculdade de Ciências Farmacêuticas, Universidade de São Paulo, SP. 


\section{INTRODUÇÃO}

Bacteriocinas são definidas como proteínas ou peptídios antimicrobianos, produzidos por bactérias, que exercem ação letal ou inibitória sobre outras bactérias. Tendo em vista sua alta eficiência como substância antibacteriana têm atraído a atenção dos pesquisadores. Seu potencial de uso parece inesgotável pelo fato de ter sido catalogada como conservante natural de alimentos (TERRA, 1997).

Lactobacillus plantarum ocorre naturalmente ou em meios desenvolvidos, como em vegetais frescos e fermentados, produtos cárneos, peixes, produtos lácteos, massas fermentadas e bebidas fermentadas (VESCOVO et al., 1993). Além de destacar-se pela rápida produção de ácido láctico, convertendo mais de $80 \%$ dos açúcares fermentescíveis (McFALL e MONTVILLE, 1989), tem sido relacionado com o desenvolvimento de atividades antimicrobianas. Constatou-se mediante testes de inibição com proteases, que as bacteriocinas são responsáveis pelo efeito inibitório sobre diversas espécies (SCHILLINGER e LÜCKE, 1989; DAESCHEL, MCKENNEY e MCDONALD, 1990).

Os açúcares exercem papel fundamental na obtenção de produto fermentado por serem redutores e servirem como fonte de carboidratos para as bactérias lácticas, usando-se normalmente açúcares de origem vegetal para esta finalidade (PARDI et al., 1994). O melaço de cana-deaçúcar, rico em açúcares fermentescíveis e minerais, é substrato adequado para o cultivo de bactérias ácido lácticas (DELGADO, 1975). Subproduto da indústria açucareira o melaço é de fácil manipulação e baixo custo apresentando grande potencial industrial a ser pesquisado.

O presente trabalho teve por objetivo detectar a presença de bacteriocinas, produzidas por L. plantarum BN, no sobrenadante obtido após a fermentação e centrifugação do melaço de cana-de-açúcar. Buscou-se determinar em que fase da curva de crescimento ocorreu a produção de bacteriocina e verificar seu efeito inibitório em relação aos patógenos Listeria monocytogenes e Staphylococcus aureus.

\section{MATERIAL E MÉTODOS}

\subsection{TESTE PARA VERIFICAR A PRODUÇÃO DE BACTERIOCINA}

A produção de bacteriocina por $L$. plantarum BN foi verificada pela técnica em gota (spot-on-the-lawn method) (LEWUS e MONTVILLE, 1991). 
Foram inoculados $5,0 \mu \mathrm{L}$ da cultura de L. plantarum BN em caldo MRS (De Man, Rogosa, Sharpe - Oxoid) em placas de Petri com $20 \mathrm{~mL}$ de TSAYE (Tripticase Soy Agar - Oxoid, com 0,6\% de extrato de levedura Difco) e incubadas em estufa (Etica, modelo 411 ) a $30^{\circ} \mathrm{C}$ por 24 horas, em anaerobiose (Jarras Probak, 2,5 L). Em seguida, verteu-se sobre a superfície da placa, aproximadamente, $8,0 \mathrm{~mL}$ de caldo BHI (Brain Heart Infusion-Oxoid) adicionado de $1,0 \%$ de ágar (Becton-Dickison) contendo microrganismo indicador $\left(10^{6} \mathrm{UFC} / \mathrm{mL}\right.$ de $L$. sakei ATCC 15521). As placas foram incubadas a $30^{\circ} \mathrm{C}$ por 24 horas, em anaerobiose, sendo observada posteriormente a formação de halos em torno da gota inoculada.

\subsection{PREPARO DO SUBSTRATO}

O melaço de cana-de-açúcar foi diluído a $3 \%(\mathrm{p} / \mathrm{v})$ e centrifugado a 4000 rpm durante 25 minutos, em centrífuga (Janetzki, modelo S60), para retirada dos sólidos em suspensão. Após a centrifugação, o meio foi enriquecido com extrato de levedura $0,5 \%$, acetato de sódio $0,5 \%$, citrato de amônio 0,2\%, Tween 80 0,1\% e sulfato de manganês $0,005 \%$, de acordo com FELTRIN (1997), sendo esterilizado a $121^{\circ} \mathrm{C}$ por 15 minutos. Em seguida, adicionou-se o fosfato de amônio 0,5\% ao meio que foi esterilizado separadamente para evitar a precipitação do mesmo.

\subsection{PREPARO DO INÓCULO}

O inóculo foi obtido a partir da cepa de L. plantarum BN ativada em $10 \mathrm{~mL}$ de caldo MRS e ressuspensa em $100 \mathrm{~mL}$ de melaço de cana-de-açúcar diluído a $3 \%$ e enriquecido. Após incubação a $30^{\circ} \mathrm{C}$ por 12 horas repetiuse por duas vezes a retirada da alíquota de $1,0 \mathrm{~mL}$ que foi ressuspensa em $100 \mathrm{~mL}$ de melaço de cana-de-açúcar 3\%, enriquecida e incubada a $30^{\circ} \mathrm{C}$ por 12 horas.

Foram retiradas alíquotas de $3 \mathrm{~mL}$ e colocadas em frascos estéreis aos quais foi adicionado glicerol estéril a $2 \%$ para evitar o ressecamento do meio e foram armazenados a $-18^{\circ} \mathrm{C}$ até sua utilização. Antes de cada fermentação, uma alíquota do inóculo foi descongelada e transferida para $100 \mathrm{~mL}$ do meio de cultivo a $30^{\circ} \mathrm{C}$ por 12 horas.

A concentração final do inóculo foi determinada utilizando-se ensaio espectrofotométrico (KANASAKI et al., 1975) e a viabilidade das células mediante contagem em placas de Petri, em profundidade, utilizando ágar MRS após 24 horas a $30^{\circ} \mathrm{C}$. 


\subsection{CULTIVO DO Lactobacillus plantarum BN}

Alíquotas de $3 \mathrm{~mL}$ do meio de cultivo contendo, aproximadamente, 9 $\mathrm{Log}_{10} \mathrm{UFC} / \mathrm{mL}$ de L. plantarum BN foram transferidas para fermentador (New Brunswick Scientific, modelo Bioflo 2000), contendo 3 L do meio de melaço de cana-de-açúcar diluído a $3 \%$ e enriquecido, com concentração final do inóculo em torno de $6 \mathrm{Log} 10 \mathrm{UFC} / \mathrm{mL}$. As condições para o cultivo foram agitação de $100 \mathrm{rpm}$, temperatura de $30^{\circ} \mathrm{C}\left( \pm 0,1^{\circ} \mathrm{C}\right)$, aeração de $0,7 \mathrm{vvm}$ (litro de ar/litro de meio/minuto) e tempo de 24 horas.

As amostras, em triplicata, foram coletadas assepticamente em frascos estéreis com intervalos de 2 horas em cada fermentação para monitoramento do processo fermentativo.

Efetuou-se a contagem de células viáveis mediante contagem padrão em placas de Petri, por profundidade, usando ágar MRS. Posteriormente, as placas foram incubadas em estufa (Etica, modelo 411) a $30^{\circ} \mathrm{C}$ por 24 horas. A densidade ótica foi estimada por leitura espectrofotométrica a 520 nm utilizando-se espectrofotômetro (MC, modelo 724), segundo KANASAKI et al. (1975). O pH foi monitorado em cada amostra coletada do fermentador usando-se potenciômetro (Schott Gerat, modelo CG 818).

\subsection{DETECÇÃO DE BACTERIOCINAS NO MELAÇO DE CANA-DE- AÇÚCAR FERMENTADO}

Alíquotas de $10 \mathrm{~mL}$ foram retiradas das amostras coletadas durante a fermentação e centrifugadas (Fanem, modelo 204-NR) a 2500 rpm por 20 minutos. Os sobrenadantes obtidos foram testados quanto à produção de bacteriocinas pelo método da difusão em orifícios (well difusion assay), proposto por LEWUS e MONTVILLE (1991).

O sobrenadante foi neutralizado a pH 7,0 com NaOH 1,0 N (Reagen) e esterilizado por filtração em membranas filtrantes (Millipore, poro 0,45 $\mu \mathrm{m}$ diâmetro $47 \mathrm{~mm}$ ). Placas com $20 \mathrm{~mL}$ de caldo BHI adicionado de $1 \%$ de ágar foram preparadas e neste meio foi adicionado o microrganismo indicador ( $10^{6} \mathrm{UFC} / \mathrm{mL}$ de L. sakei ATCC 15521). Com o auxílio de ponteira cortada e bomba de vácuo foram feitos orifícios no ágar e neles inoculados $20 \mu \mathrm{L}$ do sobrenadante filtrado, sendo as placas incubadas em anaerobiose (Jarras Probak, 2,5 L) em estufa (Etica, modelo 411) a $30^{\circ} \mathrm{C}$ por 24 horas. As placas foram observadas quanto à formação de halos em torno dos orifícios. 


\subsection{DETERMINAÇÃO DA NATUREZA PROTÉICA DO INIBIDOR}

A sensibilidade à enzima $\alpha$-quimotripsina (Sigma) foi determinada pela técnica de difusão em orifícios, adapatando-se o método descrito por HARRIS et al. (1989). Os sobrenadantes foram neutralizados a pH 7,0 com $\mathrm{NaOH} 1,0 \mathrm{~N}$ e esterilizados por filtração em membranas filtrantes. De cada sobrenadante estéril neutralizado foram retirados $40 \mu \mathrm{L}$ e colocados em poços de, aproximadamente, $5 \mathrm{~mm}$, previamente preparados nas placas de Petri contendo ágar BHI e em torno de $10^{6} \mathrm{UFC} / \mathrm{mL}$ de $L$. sakei ATCC 15521. Adjacente ao orifício contendo a cultura produtora efetuou-se outro orifício de aproximadamente $2,0 \mathrm{~mm}$, no qual foram adicionados $20 \mu \mathrm{L}$ da enzima. As placas foram mantidas na geladeira por 30 minutos para incorporação da enzima no gel de agar, sendo posteriormente incubadas em anaerobiose a $30^{\circ} \mathrm{C}$ por 24 horas.

A destruição da substância inibitória, devido à ação da enzima proteolítica, corresponde à ausência do halo próximo ao ponto de adição da $\alpha$-quimotripsina.

\subsection{VERIFICAÇÃO DA ATIVIDADE INIBITÓRIA DA BACTERIOCINA SOBRE PATÓGENOS}

As amostras que apresentaram atividade inibitória ao Lactobacillus sakei ATCC 15521 foram utilizadas para a verificação do efeito da bacteriocina sobre os patógenos L. monocytogenes ATCC 19112 e S. aureus ATCC 15489. Empregou-se a técnica da difusão em orifícios (LEWUS e MONTVILLE, 1991), nos quais os respectivos patógenos foram adicionados em substituição ao microrganismo indicador (L. sakei ATCC 15521). Foram utilizados cortes de filés (peso médio de $130 \mathrm{~g}$ ) de peito de frango, resfriados a $5{ }^{\circ} \mathrm{C}$, adquiridos no mercado de Florianópolis. A matéria-prima foi transportada em caixas térmicas até o Laboratório de Biotecnologia Alimentar da Universidade Federal de Santa Catarina.

\section{RESULTADOS E DISCUSSÃO}

\subsection{VERIFICAÇÃO DA PRODUÇÃO DE BACTERIOCINAS}

Pela técnica em gota observou-se a formação de zonas de clareamento ou halos em torno da gota do microrganismo teste (L. plantarum BN), que indicou a produção de bacteriocinas e conseqüente inibição do 
microrganismo indicador (L. sakei ATCC 15521). Para a exclusão da inibição por ação de ácidos foi utilizado meio de cultura (TSAYE) isento de glicose ou outro açúcar fermentescível pelo microrganismo. O emprego de L. sakei ATCC 15521 como cepa indicadora também diminuiu a probabilidade de inibição por ácido, já que se trata de microrganismo acidúrico. A incubação das placas em anaerobiose reduziu a inibição devido à produção de peróxido de hidrogênio.

A utilização da enzima $\alpha$-quimotripsina comprovou a natureza protéica do inibidor, uma vez que no ponto de adição da enzima houve desaparecimento da zona de clareamento e crescimento do $L$. sakei, mostrando que a bacteriocina teve sua cadeia protéica desnaturada pela protease.

A aplicação da técnica em gota confirmou estudos de LEWUS e MONTVILLE (1991) que, comparada a outros métodos de detecção, apresentou melhor visualização da zona de inibição. O método mostrouse mais rápido e fácil, não apresentando resultados falso-negativos como na técnica de difusão em orifícios.

MORENO, LERAYER e LEITÃO (1998), citam autores que verificaram que o método de antagonismo por inoculação em forma de pontos (técnica em gota) foi mais adequado, quando comparado com o de inoculação em estrias e com o de antagonismo simultâneo por inoculação em poços, devido melhor reprodutibilidade, rapidez e facilidade.

A técnica em gota também foi adotada por outros autores para a detecção de bacteriocinas (WEST e WARNER, 1988; DAESCHEL, MCKENNEY e MCDONALD, 1990; OKEREKE e MONTVILLE, 1991a; LEWUS, KAISER e MONTVILLE, 1991; LEWUS e MONTVILLE, 1992; GARVER e MURIANA, 1993; FRICOURT et al., 1994; GONZÁLEZ et al., 1994; KELLY, ASMUDSON e HUANG, 1996).

\subsection{CULTIVO DE Lactobacillus plantarum BN}

A fermentação com concentração média inicial de células viáveis de $L$. plantarum BN de 6,48 Log $10 \mathrm{UFC/mL}$ alcançou seu crescimento máximo no tempo 16 horas $\left(10,74 \log _{10} \mathrm{UFC} / \mathrm{mL}\right)$, vindo posteriormente a decrescer.

Durante a fermentação a média de $\mathrm{pH}$ diminuiu de 6,49 para 5,05, sendo proporcional ao aumento do número de células viáveis de $L$. plantarum BN (Figura 1) e indicando sua característica acidificante. 
FIGURA 1 - CURVA DE CRESCIMENTO E VALORES DE pH DE $L$. plantarum BN CULTIVADO EM MELAÇO DE CANA-DEAÇÚCAR DILUÍDO A 3\% E ENRIQUECIDO

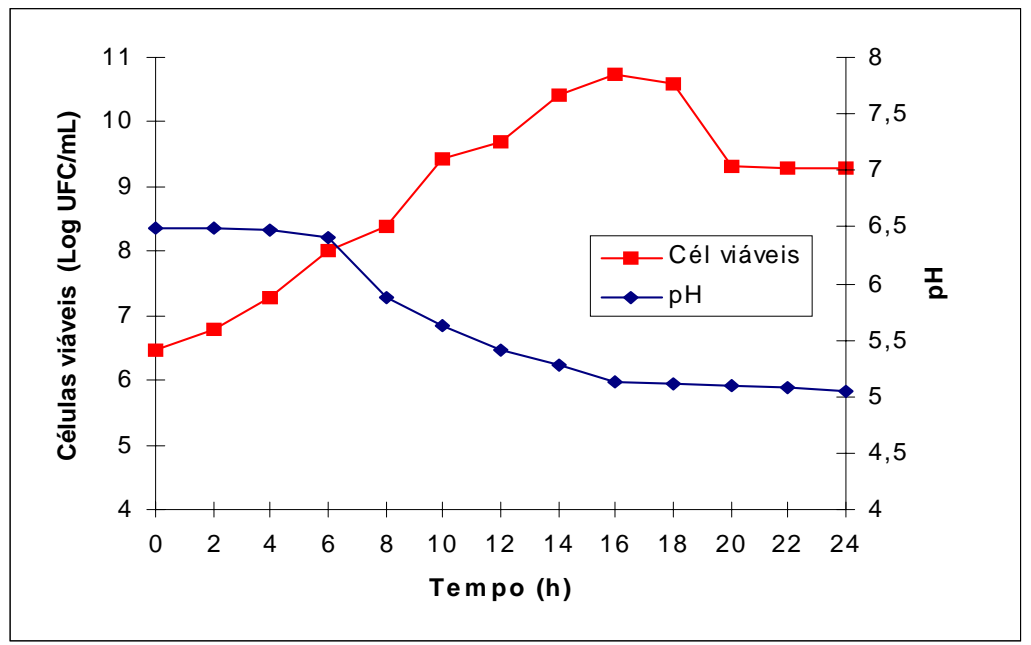

KELLY, ASMUDSON e HUANG (1996), que cultivaram L. plantarum KW30 em caldo MRS a $28^{\circ} \mathrm{C}$ por 24 horas, obtiveram decréscimo de $\mathrm{pH}$ de 6,0 para 3,8 até o final da incubação. L. plantarum LC74 inoculado em caldo MRS a $25^{\circ} \mathrm{C}$ por 24 horas apresentou comportamento semelhante ao KW30, com variação de $\mathrm{pH}$ de 6,2 para 4,0 (REKHIF, ATRIH e LEFEBVRE, 1994).

O crescimento celular foi acompanhado no decorrer da fermentação por determinação espectrofotométrica a $520 \mathrm{~nm}$, sendo a densidade ótica média final obtida no meio de cultivo utilizado de 0,469 . O pico máximo de 0,544 foi observado após 18 horas de fermentação, apresentado na Figura 2.

LEWUS e MONTVILLE (1992) estabeleceram curva de crescimento para L. plantarum BN, utilizando meio caldo APT (All Purpose Tween) a $30^{\circ} \mathrm{C}$, com leitura espectrofotométrica a $660 \mathrm{~nm}$. Após 4 horas da inoculação da cepa no caldo, a densidade ótica encontrava-se em 0,1 passando a 1,1 em 20 horas. 
FIGURA 2 - DENSIDADE ÓTICA A $520 \mathrm{~nm}$ DO CULTIVO DE $L$. plantarum BN NO MEIO DE CULTIVO DE MELAÇO DE CANA-DE-AÇÚCAR DILUÍDO A 3\% E ENRIQUECIDO

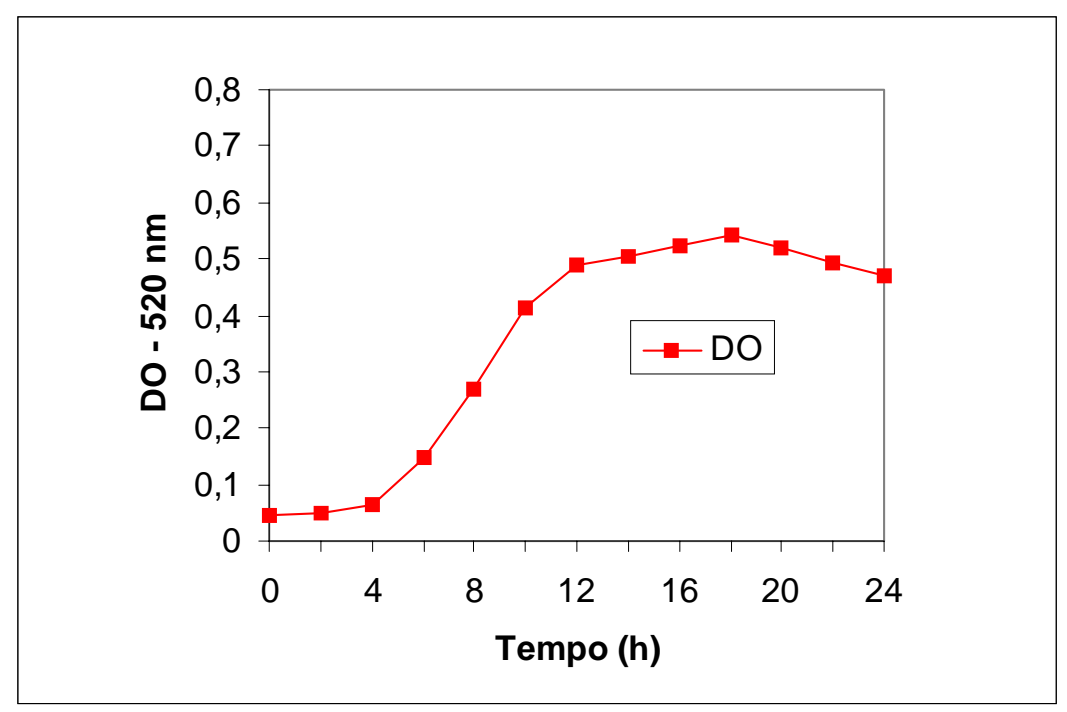

DAESCHEL, MCKENNEY e MCDONALD (1990) inocularam L. plantarum C-11 em caldo MRS a $37{ }^{\circ} \mathrm{C}$ e controlaram o crescimento celular por medida de densidade ótica a $650 \mathrm{~nm}$. Em 8 horas de fermentação o meio apresentou densidade ótica igual a 0,2, chegando a 1,0 após 20 horas.

GONZÁLEZ et al. (1994) verificaram o crescimento de L. plantarum LL441 em caldo MRS a $30^{\circ} \mathrm{C}$, em espectrofotômetro a $580 \mathrm{~nm}$. Com 5 horas de fermentação, a densidade ótica aproximou-se de 0,4, com aumento até 1,4 em 20 horas.

\subsection{DETECÇÃO DE BACTERIOCINAS EM MEIO DE CULTIVO DE MELAÇO DE CANA-DE-AÇÚCAR DILUÍDO A 3\% E ENRIQUECIDO}

No decorrer de 24 horas de fermentação foram retiradas alíquotas de $10 \mathrm{~mL}$, a cada 2 horas, as quais foram centrifugadas e o sobrenadante separado para a detecção de bacteriocinas pelo método da difusão em orifícios. O sobrenadante foi neutralizado a pH 7,0, com hidróxido de sódio, para descartar a possibilidade da inibição por ácidos. 
A visualização dos halos de inibição em torno do orifício foi possível a partir de 8 horas de fermentação, quando o microrganismo encontrava-se na fase exponencial, correspondendo a 8,57 $\log _{10} \mathrm{UFC} / \mathrm{mL}$. As zonas de clareamento foram detectadas mais facilmente nos tempos de 10 e 12 horas de fermentação. As zonas de inibição mantiveram-se até o final da fermentação com halos de tamanhos variados.

LEWUS e MONTVILLE (1992), verificando a produção de bacteriocina plantaricina BN por L. plantarum BN, observaram que a maior produção da substância inibitória também ocorreu na fase exponencial de crescimento do microrganismo. Outras bacteriocinas já foram identificadas na fase exponencial de crescimento do microrganismo (REKHIF, ATRIH e LEFEBVRE, 1995; NISSEN-MEYER et al., 1993; JIMÈNEZ-DIAZ et al., 1993; ATRIH et al., 1993b; GONZÁLEZ et al., 1994; KATO et al., 1994; REKHIF, ATRIH e LEFEBVRE, 1994).

HSICH, PAIK e GLATZ (1996) consideram o método da difusão em orifícios como um dos mais comuns para detecção e quantificação da atividade da bacteriocina, lembrando que o método apresenta desvantagens.

Segundo BENKERROWN et al. (1993), RYSER e RICHARD (1992), TOBA, SAMANT e ITOH (1991), a preparação do material e organização das placas para o teste de difusão em orifícios podem ser trabalhosos. Além disso, os resultados obtidos estão sujeitos a diversos erros, como a reprodutibilidade da concentração do microrganismo e a habilidade do pesquisador na determinação da última diluição que mostre inibição do indicador (MURIANA e LUCHANSKY, 1993). De acordo com LEWUS e MONTVILLE (1991) resultados falso-negativos nesta técnica podem ser atribuídos à agregação, a bacteriocinas não-difundíveis e a inativação por proteases. MORENO (1996) com o intuito de verificar a produção de bacteriocinas por Lactococcus observou que o método de antagonismo simultâneo por inoculação em poços permitiu a formação de halos de inibição maiores e mais consistentes. Passou a considerar este método superior ao de inoculação em forma de pontos e estrias.

LEWUS e MONTVILLE (1992) estudaram a produção de plantaricina BN em meio caldo e verificaram que esta foi inconsistente e variável. Relataram a dificuldade na obtenção de atividade da bacteriocina em meio caldo já observada em outras pesquisas.

As condições ótimas para o crescimento do microrganismo nem sempre são as mesmas para o máximo de produção de bacteriocinas, e devem 
ser determinadas experimentalmente para cada bacteriocina específica. OKEREKE e MONTVILLE (1991b) isolaram e demonstraram a atividade de bacteriocinas a $4{ }^{\circ} \mathrm{C}$ e $10^{\circ} \mathrm{C}$, cuja produção foi maior do que na temperatura ideal de crescimento do microrganismo teste $\left(30^{\circ} \mathrm{C}\right)$.

\subsection{DETERMINAÇÃO DA NATUREZA PROTÉICA DO INIBIDOR}

A natureza protéica da bacteriocina produzida em meio caldo de melaço de cana-de-açúcar diluído a $3 \%$ e enriquecido foi assegurada pelo teste com a protease $\alpha$-quimotripsina. LEWUS, KAISER e MONTVILLE (1991) comprovaram que plantaricina $\mathrm{BN}$ apresenta sensibilidade somente a $\alpha$-quimotripsina, quando testada juntamente com tripsina, pronase $\mathrm{E} e$ pepsina.

A presença da enzima nas amostras em que foi verificada a formação de halo de inibição, nos tempos de 8 a 24 horas, ocasionou o desaparecimento da porção do halo no ponto de adição. Tal fato deve-se ao rompimento da cadeia protéica, comprovando a natureza da substância inibitória.

OKEREKE e MONTVILLE (1991a) constataram a sensibilidade de plantaricina BN para outra enzima, a proteinase K. Efeito similar foi obtido com as bacteriocinas obtidas das cepas de L. plantarum Lb75 e Lb 592, sendo que a primeira demonstrou igual sensibilidade para $\alpha$-quimotripsina e pronase $\mathrm{E}$.

A sensibilidade à proteases constitui critério fundamental na caracterização de inibidores como bacteriocinas. Outras bacteriocinas de $L$. plantarum também apresentaram sensibilidade a uma ou mais proteases (WEST e WARNER, 1988; JIMÈNEZ-DIAZ et al., 1993; ATRIH et al., 1993b; GONZÁLEZ et al., 1994; KATO et al., 1994; FRICOURT et al., 1994; KELLY, ASMUDSON e HUANG, 1996; ATRIH et al.,1993a).

\subsection{VERIFICAÇÃO DA ATIVIDADE INIBITÓRIA DA BACTERIOCINA SOBRE PATÓGENOS}

Após constatar-se que substância inibitória era bacteriocina foi realizado o teste de difusão em orifícios, para verificar o efeito inibitório da mesma sobre Listeria monocytogenes ATCC 19112 e Staphylococcus aureus ATCC 15489. Verificou-se a formação de halo de inibição quando foi testada $L$. monocytogenes ATCC 19112 em substituição ao microrganismo indicador 
(L. sakei ATCC 15521), evidenciando que a cepa utilizada no teste foi sensível à bacteriocina produzida por $L$. plantarum $B N$ no meio de melaço de cana-de-açúcar a 3\% e enriquecido. No teste com S. aureus ATCC 15489 não houve formação de halo de inibição, constatando-se que a cepa utilizada foi resistente a bacteriocina produzida por $L$. plantarum BN. O mesmo foi observado por LEWUS, KAISER e MONTVILLE (1991) ao testarem a sensibilidade de patógenos por diversas cepas produtoras de bacteriocinas, entre as quais $L$. plantarum $B N$. Verificaram que cepas de $L$. monocytogenes Scott A, V7, $101 \mathrm{~m}$ e $103 \mathrm{~m}$ foram inibidas por $L$. plantarum BN, enquanto que as cepas de Staphylococcus aureus 25923 e 196E foram resistentes.

As bacteriocinas produzidas por L. plantarum Lb592 e Lb75 apresentaram espectro inibitório semelhante ao da cepa BN quanto à inibição de $L$. monocytogenes Scott A, V7, $101 \mathrm{~m}$ e 103 m, porém essas substâncias também inibiram S. aureus 25923 e 196E (LEWUS, KAISER e MONTVILLE, 1991).

De forma similar a plantaricina BN, outras bacteriocinas produzidas por L. plantarum apresentaram atividade inibitória sobre L. monocytogenes (ENAN et al., 1996; COVENTRY et al., 1997; ATRIH et al., 1993b; FRICOURT et al., 1994; REKHIF, ATRIH e LEFEBVRE, 1994; JEPPESEN e HUSS, 1993). As plantaricinas como a S (JIMÈNEZ-DIAZ et al., 1993), a A (DAESCHEL et al., 1990), a 149 (KATO et al., 1994) e a KW30 (KELLY, ASMUDSON e HUANG, 1996), no entanto não apresentaram atividade inibitória sobre $L$. monocytogenes. A ausência de efeito inibitório contra algumas cepas de $S$. aureus também foi demonstrada por plantaricina C19 (ATRIH et al., 1993b), 149 (KATO et al., 1994) e plantaricina 154 (KANATANI e OSHIMURA, 1994). De maneira contrária, as plantaricinas C19 (ATRIH et al., 1993b), 83 (ANDERSSON, 1986), $\mathrm{F}$ (FRICOURT et al., 1994) e LC74 (REKHIF, ATRIH e LEFEBVRE, 1994) foram efetivas sobre cepas de $S$. aureus.

\section{CONCLUSÃO}

Foi detectada a presença de bacteriocinas produzidas por Lactobacillus plantarum BN no sobrenadante obtido após fermentação e centrifugação do meio de cultivo de melaço de cana-de-açúcar diluído a 3\% e enriquecido. A produção ocorreu durante a fase exponencial de crescimento do microrganismo e a bacteriocina produzida exerceu atividade inibitória sobre Listeria monocytogenes ATCC 19112. 


\begin{abstract}
DETECTION OF BACTERIOCIN PRODUCED BY Lactobacillus plantarum BN IN SUGAR-CANE MOLASSES BY SUBMERSE FERMENTATION

The presence of bacteriocins produced by Lactobacillus plantarum BN (test microorganism) in 3\% sugar cane molasses, centrifuged and enriched with yeast extract, sodium acetate and ammonium citrate, was verified. The tests were realized in a fermenter with $3.0 \mathrm{~L}$ work volume, under continuous agitation of $100 \mathrm{rpm}$, at a temperature of $30 \pm$ $0.1^{\circ} \mathrm{C}, 0.7 \mathrm{vvm}$ aeration and fermentation time of 24 hours with an approximate inoculum of $6.0 \log _{10} \mathrm{CFU} / \mathrm{mL}$ with sample being taken at every 2 hours interval. The greatest number of viable cells observed was $10 \log _{10}$ logarithmic cycles at 12 and 18 hours fermentation intervals. Initial pH was 6,49 and after 24 hours, it decreased to 5,05 . Bacteriocins detection was accomplished using the supernatant obtained by centrifugation of cultivation media in the well diffusion method using Lactobacillus sakei ATCC 15521 as the indicator microorganism. From 8 hours on of fermentation, presence of colonies surrounded by a clear zone of inhibition indicated bacteriocins production in cultivation media when the microorganism was in the exponential growth phase. The proteic nature of the bacteriocin was certified by using the $\alpha$-chimotrypsin enzyme. The bacteriocin produced by Lactobacillus plantarum BN presented inhibiting effect over Listeria monocytogenes ATCC 19112 while this effect was not observed in Staphylococcus aureus ATCC 15489.
\end{abstract}

KEY WORDS: LACTOBACILLUS PLANTARUM BN; BACTERIOCINS; SUGAR-CANE MOLASSES; FERMENTATION.

\title{
REFERÊNCIAS
}

1 ANDERSSON, R. Inhibition of Staphylococcus aureus and spheroplasts of Gram-negative bacteria by a antagonistic compound produced by a strain of Lactobacillus plantarum. International Journal of Food Microbiology, v. 3, p.149-160, 1986.

2 ATRIH, A. et al. Detection of bacteriocins produced by Lactobacillus plantarum strains isolated from different foods. Microbios, v. 75, p.117123, 1993a.

3 ATRIH, A. et al. Detection and characterization of a bacteriocin produced by Lactobacillus plantarum C19. Canadian Journal of Microbiology, v.39, n.12, p.1173-1179, 1993b.

4 BENKRROUM, N. et al. Methods to demonstrate the bactericidal activity of bacteriocins. Lett. App. Microb., v.17, p.78-81, 1993.

5 COVENTRY, M.J. et al. Detection of bacteriocins of lactic acid bacteria isolated from foods and comparison with pediocin and nisin. 
J. App. Microb., v.83, p.248-258, 1997.

6 DAESCHEL, M.A. et al. Bactericidal activity of Lactobacillus plantarum C-11. Food Microb., v.7, p.91-98, 1990.

7 DELGADO, A.A. Tecnologia do açúcar e das fermentações industriais: tecnologia dos produtos agropecuários I. Piracicaba: Escola Superior de Agricultura Luiz de Queiroz, 1975.

8 ENAN, G. et al. Antibacterial activity of Lactobacillus plantarum UG1 isolated from dry sausage: characterization, production and bactericidal action of plantaricin UG1. International Journal of Food Microbiology, v.30, p.189-215, 1996.

9 FELTRIN, V.P. Produção de Lactobacillus plantarum em meio de cultura à base de melaço de cana-de-açúcar. Florianópolis: UFSC, 1997. 60 p. Dissertação (Mestrado em Ciência dos Alimentos) - Departamento de Ciência e Tecnologia dos Alimentos, Universidade Federal de Santa Catarina.

10 FRICOURT, B.V. et al. Detection and activity of plantaricin F an antibacterial substance from Lactobacillus plantarum BF001 isolated of processed channel catfish. Journal of Food Protection, v.57, p.698-702, 1994.

11 GARVER, K.I.; MURIANA, P.M. Detection, identification and characterization of bacteriocin-producing lactic acid bacteria from retail food products. Int. J. Food Microb., v.19, p.241-258, 1993.

12 GONZÁLEZ, B. et al. Detection, purification, and partial characterization of plantaricin $\mathrm{C}$, a bacteriocin produced by a Lactobacillus plantarum strain of dairy origin. Applied and Environmental Microbiology, v.60, p.2158-2163, 1994.

13 HARRIS, L.J.; et al. Antimicrobial activity of lactic acid bacteria against Listeria monocytogenes. Journal of Food Protection, v.51, p.2931, 1989.

$14 \mathrm{HSICH}, \mathrm{H}$.; PAIK, H.; GLATZ, B.A Improvement of detection and production of propiocin PLG-1, a bacteriocin produced by Propionibacterium thoenii. Journal of Food Protection, v.59, n.7, p.734-738, 1996. 
15 JEPPENSEN, V.F.; HUSS, H.H. Antagonistic activity of two strains of lactic acid bacteria against Listeria monocytogenes and Yersinia enterocolitica in a model fish product at $5^{\circ} \mathrm{C}$. International Journal of Food Microbiology, v.19, p.179-186, 1993.

16 JÍMENEZ-DÍAZ, R. et al. Plantaricins $\mathrm{S}$ and T, two new bacteriocins produced by Lactobacillus plantarum LPCO10 isolated from a green olive fermentation. Applied and Environmental Microbiology, v. 59, p.1416-1424, 1993.

17 KANASAKI, M. et al. Effects of temperature on the growth and acid production of lactic acid bacteria. Australian Journal Food Protection, v. 30, n.4, p. 142-144, 1975.

18 KANATANI, K.; OSHIMURA, M. Plasmid-associated bacteriocin production by a Lactobacillus plantarum strain. Bioscience, Biotechnology, Biochemistry, v.58, p.2084-2086, 1994.

19 KATO, T. et al. Plantaricin-149, a bacteriocin produced by Lactobacillus plantarum NRIC149. Journal of Fermentation and Bioengineering, v.77, p.277-282, 1994.

20 KELLY, W.J.; ASMUDSON, R.V.; HUANG, C.M. Characterization of plantaricin KW30, a bacteriocin produced by Lactobacillus plantarum. Journal of Applied Bacteriology, v.81, p.657-662, 1996.

21 LEWUS, C.B., KAISER, A.; MONTVILLE, T.J. Inhibition of food-borne bacterial pathogens by bacteriocins from lactic acid bacteria isolated from meat. Applied and Environmental Microbiology, v.57, p.1683-1688, 1991.

22 LEWUS, C.B.; MONTVILLE, T.J. Detection of bacteriocins produced by lactic acid bacteria. Journal of Microbiology Methods, v.13, p.145-150, 1991. . Further characterization of bacteriocins plantaricin $\mathrm{BN}$, bavaricin $\mathrm{MN}$ and pediocin A. Food Biotechnology, v.6, n.2, p.153174, 1992.

24 McFALL, S.M.; MONTVILLE, T.J. pH-mediated regulation of pyruvate catabolism in Lactobacillus plantarum chemostat cultures. Journal Ind. Microbiology, v. 4, p.335-340, 1989. 
25 MORENO, I. Ocorrência e caracterização de bacteriocinas de lactococos e sua utilização no processamento de queijo minas frescal. São Paulo: USP, 1996. Dissertação (Mestrado em Ciência dos Alimentos) - Faculdade de Ciências Farmacêuticas, Universidade de São Paulo.

26 MORENO, I.; LERAYER, A.L.S.; LEITÃO, M.F.F. Métodos utilizados para a detecção e avaliação da atividade de bacteriocinas de bactérias lácticas. Indústria de Laticínios, São Paulo, p.67-69, mar./abr. 1998.

27 MURIANA, P.M.; LUCHANSKY, J.B. Biochemical methods for purification of bacteriocins. In: HOOVER, D.G.; STEENSON, L.R. Bacteriocins of lactic acid bacteria. San Diego: Academic Press, 1993. p. 41-61.

28 NISSEN-MEYER, J. et al. Purification and characterization of plantaricin A, a Lactobacillus plantarum bacteriocin whose activity depends on the action of two peptides. Journal of General Microbiology, v.139, p.1973-1978, 1993.

29 OKEREKE, A.; MONTVILLE, T.J. Bacteriocin inhibition of Clostridium botulinum spores by lactic acid bacteria. Journal of Food Protection, v.54, n.5, p.349-353, 1991a.

30 B Bacteriocin mediated inhibition of Clostridium botulinum spores by lactic acid bacteria at refregeration and abuse temperatures. Apllied and Environmental Microbiology, v.57, p. 3423-3428, 1991b.

31 PARDI, M.C. et al. Ciência, higiene e tecnologia da carne. Goiânia: CEGRAF-UFG, 1994.

32 REKHIF, N.; ATRIH, A.; LEFEBVRE, G. Characterization and partial purification of plantaricin LC74, a bacteriocin produced by Lactobacillus plantarum LC74. Biotechnology Letters, v.16, p.771776, 1994.

Activity of plantaricin SA6, a bacteriocin produced by Lactobacillus plantarum SA6 isolated from fermented sausage. Journal of Applied Bacteriology, v.78, p.349-358, 1995. 
34 RYSER, E.T.; RICHARD, J.A. Detection of bacteriocin activity in bacteria using hydrophobic grid membrane filters. Letters in Applied Microbiology, v.14, n.3, p.104-107, 1992.

35 SCHILLINGER, U.; LÜCKE, F.K. Antimicrobial activity of Lactobacillus sake isolated from meat. Applied and Environmental Microbiology, v.55, p.1901-1906, 1989.

36 TERRA, N.N. Fermentação como fator de segurança e qualidade para o consumidor. Revista Nacional da Carne, v.21, p.26-32, 1997.

37 TOBA, T.; SAMANT, S.K.; ITOH, T. Assay system for detecting bacteriocins in microdilution wells. Letters Apllied Microbiology, v.13, p.102-104, 1991.

38 VESCOVO, M. et al. Basic characteristics, ecology and application of Lactobacillus plantarum: a review. Ann. Microbiol. Enzimol., v.43, p.261-284, 1993.

39 WEST, C.A; WARNER, P.J. Plantacin B, a bacteriocin produced by Lactobacillus plantarum NCDO 1193. FEMS Microbiology Letters, v.49, p.163-165, 1988. 